\title{
ASSISTÊNCIA ESTUDANTIL E PROCESSOS DE TRABALHO DA EQUIPE MULTIDISCIPLINAR NO IFS - CAMPUS LAGARTO
}

\author{
STUDENT ASSISTANCE AND WORKING PROCESSES OF THE
}

MULTIDISCIPLINARY TEAM AT IFS - CAMPUS LAGARTO

\author{
Ana Paula Leite Nascimento ${ }^{1}$ \\ Fábio Kalil de Souza ${ }^{2}$ \\ Débora Lima Siqueira ${ }^{3}$
}

\begin{abstract}
RESUMO: O estudo realizou uma reflexão teórica e prática do exercício profissional, evidenciando a particularidade do processo de trabalho da equipe multidisciplinar na Assistência Estudantil, com análises da atuação nas áreas de Serviço Social, Pedagogia e Psicologia no IFS - Campus Lagarto. Configurou-se enquanto pesquisa qualitativa com abordagem descritiva e explicativa dos processos de trabalho, recorrendo-se ao levantamento bibliográfico e da legislação e à sistematização da atuação profissional em demandas da política de Assistência Estudantil. Como resultados, essa investigação possibilitou problematizar dimensões inerentes à política de Educação e Assistência Estudantil e expor a processualidade técnica e interventiva que direciona o trabalho desenvolvido pela equipe multidisciplinar. Agregou contribuições às práticas e às respostas profissionais, sejam elas específicas por área técnica ou de cunho multidisciplinar, fortalecendo a discussão técnica das demandas entre a equipe para uma atuação fundamentada, cada vez mais, em premissas teóricas e analíticas.
\end{abstract}

Palavras-chave: Educação. Assistência Estudantil. Processos de Trabalho Multidisciplinares.

\begin{abstract}
The study carried out a theoretical and practical reflection of professional practice, showing the particularity of the work process of the multidisciplinary team in Student Assistance, with analyzes of the performance in the areas of Social Service, Pedagogy and Psychology at IFS - Campus Lagarto. It was configured as a qualitative research with a descriptive and explanatory approach to work processes, using bibliographic and legislation surveys and systematizing professional performance in terms of Student Assistance policy demands. As a result, this investigation made it possible to problematize dimensions inherent to the Education and Student Assistance policy and expose the technical and interventional procedure that guides the work developed by the multidisciplinary team. It added contributions
\end{abstract}

\footnotetext{
${ }^{1}$ Assistente social; Instituto Federal de Educação, Ciência e Tecnologia de Sergipe (IFS), Campus Lagarto, lotada na Gerência de Ensino Básico e Técnico, ingresso em 2009; Pós-Doutoranda em Educação, Doutora em Educação; Estrada da Barragem, Jardim Campo Novo, Lagarto - SE, 49400-000; (79) 3321-1500; ORCID iD: https://orcid.org/0000-0002-2050-1596; E-mail: paula.leite@ifs.edu.br.

${ }^{2}$ Pedagogo; Instituto Federal de Educação, Ciência e Tecnologia de Sergipe (IFS), Campus Lagarto, lotado na Gerência de Ensino Básico e Técnico, ingresso em 2008; Doutorando em Educação, Mestre em Educação; Estrada da Barragem, Jardim Campo Novo, Lagarto - SE, 49400-000; (79) 3321-1509; ORCID iD: https://orcid.org/00000002-0323-5791; E-mail: fabioksouza@gmail.com.

3 Psicóloga; Instituto Federal de Educação, Ciência e Tecnologia de Sergipe (IFS), Campus Lagarto, lotada na Gerência de Ensino Básico e Técnico, ingresso em 2014; Especialista em Psicodrama e em Psicologia Organizacional e do Trabalho; Estrada da Barragem, Jardim Campo Novo, Lagarto - SE, 49400-000; (79) 33211500; ORCID iD: https://orcid.org/0000-0002-7611-6646; E-mail: debora.siqueira@,ifs.edu.br.
} 
to professional practices and responses, whether specific by technical area or of a multidisciplinary nature, strengthening the technical discussion of the demands between the team for a performance based, increasingly, on theoretical and analytical premises.

Key-words: Education. Student Assistance. Multidisciplinary Work Processes.

\section{INTRODUÇÃO}

Essa pesquisa se propôs a realizar uma reflexão teórica e do exercício profissional, particularizando o processo de trabalho da equipe multidisciplinar na Assistência Estudantil, bem como trazer à tona as experiências da atuação e das intervenções das áreas de Serviço Social, Pedagogia e Psicologia no âmbito do Instituto Federal de Educação, Ciência e Tecnologia de Sergipe (IFS) - Campus Lagarto.

Para compreender o contexto no qual estamos inseridas/os, é importante demarcar que trabalhamos em uma instituição que sofreu grandes mudanças nos últimos 12 anos. O IFS faz parte de um grupo de antigas Escolas Técnicas Federais, assim como Agrotécnicas (parte delas surgidas em 1909 no governo do presidente Nilo Peçanha), que no final de 2008 aderiram ao processo de Ifetização proposto pelo Governo Federal, por meio da Lei n ${ }^{\circ} 11.892$, se tornando Institutos Federais de Educação, Ciência e Tecnologia. Na adesão, o IFS foi criado com três campi e atualmente conta com dez campi (nove em funcionamento e um em fase de implantação) que cobrem praticamente todas as regiões do estado de Sergipe.

Essa breve contextualização da criação dos Institutos Federais e ampliação do IFS onde nos inserimos, como profissionais, se faz necessária porque algumas/uns profissionais estavam realizando suas práticas antes desse processo de mudança da institucionalidade, enquanto outras/os adentraram nesse novo formato. Diante deste fato, temos, muitas das vezes, experiências diversificadas e que apesar de se encontrarem em diversos pontos, diferenciam-se em muitos outros.

Neste artigo trouxemos à baila notas sobre a política de Educação e de Assistência Estudantil ilustrando bases teóricas, e devido à especificidade do estudo apresentamos a atuação do Serviço Social na Assistência Estudantil, da Pedagogia e da Psicologia também em suas assistências estudantis peculiares, todas as experiências e práticas no IFS - Campus Lagarto. Do ponto de vista metodológico, a pesquisa se constitui como qualitativa com abordagem descritiva e explicativa dos processos de trabalho em diálogo com o aporte teórico que subsidia a contextualização e análise. Houve levantamento bibliográfico, de legislação e sistematização da atuação profissional em interface com as demandas de Assistência Estudantil e respectivas respostas/intervenções profissionais, considerando as atribuições e competências profissionais. 
A dimensão técnica-operacional do exercício profissional foi visibilizada e circunstanciada por reflexões teóricas e analíticas, sem caracterizar-se mera exposição da rotina de trabalho, pois torna-se imperativo reflexionar o processo de trabalho para não incorrer em prática mecanicista.

\section{NOTAS SOBRE A POLÍTICA DE EDUCAÇÃO E ASSISTÊNCIA ESTUDANTIL}

A trajetória da política educacional no Brasil “evidencia como as desigualdades sociais são reproduzidas a partir dos processos que restringiram, expulsaram e hoje buscam 'incluir' na educação escolarizada largos contingentes da classe trabalhadora". (CFESS, 2013, p. 20). Apesar de a educação constituir-se como um direito social, apresenta-se como uma das áreas em que a questão da desigualdade se reflete com maior nitidez na sociedade brasileira. Essa realidade impõe desafios às/aos estudantes pertencentes à classe trabalhadora, denominadas/os como sujeitas/os das classes populares, que enfrentam maiores dificuldades e desafios no acesso e permanência na escola, demandando ao mesmo tempo a democratização das condições de acesso e permanência no cotidiano acadêmico-escolar. (NASCIMENTO, 2014).

Considerando essa configuração estrutural, o direito à educação não pode se restringir somente à ampliação das possibilidades de acesso; mostra-se imprescindível também a criação de mecanismos que possam garantir a permanência e a conclusão dos cursos e projetos acadêmicos e profissionais das/os estudantes oriundas/os da classe trabalhadora que ingressam nas instituições educacionais. (NASCIMENTO, 2014). O conjunto de ações e os mecanismos propostos para viabilizar tal permanência constituem a Assistência Estudantil “[...] enquanto política de enfrentamento ao velho e crônico enigma da evasão, da repetência e, especialmente, das desigualdades econômicas, sociais e culturais, como traços presentes na educação brasileira". (NASCIMENTO, 2014, p. 73 , grifos originais).

A Assistência Estudantil deve ser concebida como direito das/os estudantes às ações de acesso e de permanência desenvolvidas com recursos públicos nas instituições educacionais, contrariando, pois, as tentativas de associação dessas ações, programas e serviços a práticas de assistencialismo e a benesse. Referendamos, portanto, a Política de Assistência Estudantil como "direito social capaz de romper com as tutelas assistencialistas e com concessões estatais, com vistas à [...] formação plena, produção de conhecimento, melhoria do desempenho acadêmico e o bem-estar biopsicossocial”. (PAZ, 2012, p. 193).

As ações de Assistência Estudantil surgem a partir de reivindicações em defesa do provimento, por parte das instituições educacionais e do Estado, das condições necessárias à democratização do acesso e da permanência das/os estudantes. (NASCIMENTO, 2012). Faz- 
se necessário atentar-se à leitura crítica das necessidades estudantis enquanto diretriz norteadora para a formulação das ações de assistência ao público que demanda suas intervenções profissionais e institucionais. De acordo com o Programa Nacional de Assistência Estudantil (Pnaes), Artigo $3^{\circ}$, parágrafo $1^{\circ}$, as ações de Assistência Estudantil deverão ser desenvolvidas nas áreas de: I. moradia estudantil; II. alimentação; III. transporte; IV. atenção à saúde; V. inclusão digital; VI. cultura; VII. esporte; VIII. creche; IX. apoio pedagógico; e X. acesso, participação e aprendizagem de estudantes com deficiência, transtornos globais do desenvolvimento e altas habilidades e superdotação. (BRASIL, 2010). A promulgação do Pnaes significou "a consolidação de uma luta histórica em torno da garantia da assistência estudantil enquanto um direito social voltado para igualdade de oportunidades [às/aos] estudantes". (VASCONCELOS, 2012, p. 105-106, acréscimos nossos).

A Política de Assistência Estudantil do IFS objetiva desenvolver projetos, linhas de ação e serviços que assegurem às/aos estudantes o acesso, a permanência e o êxito em seu percurso educacional, consolidando o apoio à formação integral e contribuindo preventivamente nos casos de evasão e retenção. O público-alvo é constituído das/os estudantes regularmente matriculadas/os e daquelas/es que estejam em mobilidade nacional e internacional. As ações de Assistência Estudantil são desenvolvidas pelo Programa de Acompanhamento e Assistência ao Educando (Praae): programa institucional composto por projetos, linhas de ações e serviços desenvolvidos e executados pela Coordenação de Assuntos Estudantis (Coae) de cada Campus e por profissionais das equipes multidisciplinares dos campi, acompanhados pela Diretoria de Assuntos Estudantis (Diae). As ações universais do Praae são projetos, auxílios financeiros e bolsas que independem da situação de vulnerabilidade socioeconômica. As ações específicas são projetos, auxílios financeiros e bolsas que dependem da situação de vulnerabilidade socioeconômica. Cabe pontuar que a seleção das/os estudantes em tal vulnerabilidade, a serem beneficiadas/os com auxílios ou bolsas das linhas de ações de vulnerabilidade socioeconômica, é realizada pelas/os assistentes sociais por meio de editais específicos. (IFS, 2017).

\section{ATUAÇÃO DO SERVIÇO SOCIAL NA ASSISTÊNCIA ESTUDANTIL}

Nessa seção, a ênfase será dada às abordagens sociais, aos instrumentos de trabalho e às intervenções profissionais da área de Serviço Social; também a algumas ações articuladas com outras áreas, categorias profissionais e/ou instituições, considerando as experiências do trabalho presencial e do recente teletrabalho (remoto) no contexto da Pandemia Covid-19. 
As demandas e necessidades estudantis requerem análises e respostas profissionais que perpassam as dimensões teórico-metodológica, ético-política e técnico-operativa que norteiam o exercício profissional das/os assistentes sociais. No cotidiano profissional se impõe a necessidade de articular essas dimensões com o propósito de "[...] identificar e construir estratégias que venham a orientar e instrumentalizar a ação profissional, permitindo não apenas o atendimento das demandas imediatas e/ou consolidadas, mas sua reconstrução crítica" (GUERRA, 2009, p. 1), viabilizando as respostas e intervenções profissionais em forma de serviços, programas e projetos através da intersetorialidade entre as políticas sociais e em ação inter e multidisciplinar, conforme demandas atendidas.

Em vista disso, compete às/aos assistentes sociais "[...] atuar em direção do estabelecimento das condições materiais necessárias a uma intervenção profissional que supere a prática burocratizada, imediatista, reformista". (GUERRA, 2011, p. 29). Explicitaremos a seguir algumas intervenções profissionais relativas à atuação do Serviço Social na Assistência Estudantil do IFS.

Atendimento, acolhimento, escuta social e orientações presenciais e remotas às/aos estudantes e às/aos familiares com intervenções em demandas atreladas aos Auxílios do Praae/IFS, majoritariamente os Auxílios Permanência Estudantil, Residência, Financeiro Eventual e Emergencial de Inclusão Digital; ainda junto às vulnerabilidades socioeconômicas, sociodigitais, socioafetivas, sociofamiliares; às condições de estudos; ao Ensino Remoto Emergencial; aos Editais para empréstimos de Equipamentos Tecnológicos - Tablets Educacionais; aos impactos do isolamento e distanciamento social com a Pandemia Covid-19; aos conflitos e desafios familiares; à acessibilidade; às sexualidades; aos projetos acadêmicos e profissionais; às demandas de saúde em diálogo com outras categorias profissionais e instituições para os encaminhamentos institucionais internos e externos; além de outras demandas que surgem diuturnamente e exigem análises e respostas técnicas do Serviço Social.

Acolhimento presencial e virtual às/aos estudantes e às/aos familiares com abordagens sobre o trabalho realizado pelo Serviço Social, socialização de informações e orientações relacionadas às ações da Política de Assistência Estudantil do IFS e outras políticas sociais; abordagens individuais e/ou coletivas interdisciplinares e trabalhos em grupo para atendimentos de demandas e necessidades estudantis; plantões de atendimentos e orientações no Instagram institucional, com a intervenção multidisciplinar de categorias profissionais que o IFS dispõe e atuam em ações de Assistência Estudantil, discutindo e encaminhando os casos. 
Estudos socioeconômicos com análises socioeconômicas e documental, entrevistas, visitas domiciliares e/ou junta social, a depender da particularidade da demanda e das vulnerabilidades para a inserção nos auxílios e/ou bolsas das linhas de ações de vulnerabilidade socioeconômica do Praae/IFS. Houve um período que análises socioeconômicas eram feitas para a isenção da taxa do exame de seleção das/os estudantes ingressantes e também como ação vinculada ao ingresso das/os estudantes por meio das cotas sociais e/ou raciais.

Visitas domiciliares em demandas dos estudos socioeconômicos para: o resultado final das solicitações dos Auxílios do Praae; a elaboração de Parecer social em demanda do Auxílio Financeiro Eventual; o acompanhamento das/os estudantes que recebem auxílios financeiros do Praae; a captação de elementos da realidade estudantil e do respectivo núcleo familiar a partir de demandas apresentadas pelas/os estudantes, familiares, docentes ou outras/os profissionais que socializam casos para intervenção do Serviço Social e/ou da equipe multidisciplinar.

Visitas institucionais em unidades hospitalares para acolhimento, suporte e orientações às/aos estudantes e familiares, bem como articulações e intervenções com as/os profissionais que as/os atendem ou acompanham, objetivando ações inter e multidisciplinares; e em equipamentos e unidades da rede de proteção socioassistencial e de outras políticas públicas para mapeamento dos serviços, programas e projetos disponíveis, a fim de repasses de demandas e encaminhamentos para atendimento e acompanhamento nessas instituições.

Pareceres e relatórios sociais face às demandas estudantis e institucionais, a exemplo dos casos: 1. Solicitação de Auxílio Financeiro Eventual para atendimentos às demandas de saúde e vulnerabilidades socioeconômicas, devido à necessidade de acessar recursos financeiros para custear despesas de acompanhamento psiquiátrico; tratamento medicamentoso, oftalmológico, oncológico; cirurgias emergenciais; compras de óculos para corrigir distorções ópticas que comprometem o desempenho nas atividades acadêmicas e rotineiras do cotidiano. 2. Solicitação de Auxílio Financeiro Eventual para atendimentos às demandas de acessibilidade e vulnerabilidades sociodigitais, vez que, para o desenvolvimento das atividades escolares, é imprescindível utilizar sistemas computacionais, softwares e tecnologias assistivas. 3. Solicitação de Auxílio Financeiro Eventual para atendimentos às demandas de saúde, vulnerabilidades socioeconômicas e socioemocionais, tendo em vista a gravidez precoce, além da complexidade e dos desafios da condição de mãe solo ${ }^{4}$ em algumas experiências, apresentando necessidades

\footnotetext{
${ }^{4} \mathrm{O}$ termo mãe solo vem ganhando popularidade e alcança crescente substituição ao termo "mãe solteira". Essa mudança se deve pela carga negativa que a segunda expressão traz consigo, como se faltasse algo. O número de crianças criadas em um lar monoparental, isto é, que moram apenas com a mãe ou com o pai, vem crescendo. De acordo com dados do Instituto Brasileiro de Geografia e Estatística, entre 2005 e 2015, o país ganhou 1,1 milhão
} 
de cuidados e atenção à saúde da gestante e criança. 4. Identificação de vulnerabilidades socioeconômicas, sociodigitais, socioafetivas, sociofamiliares e condições insalubres no convívio familiar que afetam diretamente as rotinas escolares, comprometendo os projetos acadêmicos e profissionais, com repasses e intervenção junto ao Conselho Tutelar.

Acolhimento, orientações e encaminhamentos internos e externos como intervenção específica da área de Serviço Social, também intervenções interdisciplinares junto às categorias profissionais da instituição ou profissionais da rede de serviços de outras políticas sociais, haja vista a necessidade da intersetorialidade nas intervenções profissionais e entre as políticas sociais, considerando as múltiplas vulnerabilidades e as/os sujeitas/os sociais em sua totalidade.

Participação em comissões institucionais que abordam demandas da Assistência Estudantil: comissão de regulamentação dos auxílios e/ou bolsas; construção e reformulação da Política de Assistência Estudantil; implantação de sistema para operacionalização da Assistência Estudantil; elaboração de regulamento de adaptação curricular para estudantes que possuem deficiências e/ou necessidades específicas; comissão de heteroidentificação étnico racial. Elaboração e desenvolvimento de projetos de intervenção, pesquisa e extensão sobre demandas e necessidades estudantis; elaboração de cartilhas educativas e informativas para acolher e orientar às/aos estudantes, familiares e docentes, entre outras.

Participação em reuniões presenciais e virtuais com estudantes; pais, mães e/ou responsáveis; com servidoras/es do IFS vinculadas/os às equipes multidisciplinares do Campus Lagarto e multidisciplinares sistêmicas do IFS, junto à gestão do Campus Lagarto e sistêmica da Diae, à gestão sistêmica do Núcleo de Acessibilidade e Educação Inclusiva (Naedi) e aos Núcleos de Apoio às Pessoas com Necessidades Específicas (Napnes) dos campi, à gestão sistêmica da Pró-reitoria de Ensino (Proen) e da Reitoria. Participação em reuniões dos Conselhos de Classe no intuito de discutir e deliberar acerca de demandas e necessidades estudantis em uma perspectiva de defesa e garantia das condições de acesso e permanência.

Participação e realização de palestras, seminários, fóruns, projetos socioeducativos, oficinas, rodas de conversas, cine debates, priorizando temáticas que envolvem necessidades estudantis, especialmente pautas de prevenção ao suicídio; respeito às diversidades e

\footnotetext{
de famílias compostas por mães solos. No último ano da pesquisa, os pais solos representavam apenas 3,6\% das famílias com filhas/os, o número das mães foi mais expressivo com $26,8 \%$. O universo da maternidade solo é envolto por uma enxurrada de desafios socioeconômicos, socioemocionais, entre outros. Dados do Instituto Brasileiro de Geografia e Estatística de 2018 apontaram mais de 11 milhões de mulheres que, entre preocupações e medos, precisam lidar com as responsabilidades que envolvem sustentar a casa, sozinha. No contexto da Pandemia Covid-19, os cuidados precisaram aumentar e junto deles intensificaram-se o peso da insegurança e a solidão. (BETHLEM; MARTELLI; DOMS, 2019; SOUZA, 2020).
} 
enfrentamentos às práticas LGBTfóbicas; combate ao racismo, machismo, sexismo, misoginia, violências e opressões de gênero, feminicídio, regulações cis-heteronormativas; positivação das identidades e sexualidades LGBTQIA+ e valorização às culturas e subjetividades juvenis.

Acompanhamento, orientações e estímulo à participação política e ao protagonismo juvenil, com o objetivo de fortalecimento das entidades representativas estudantis, de acolhimento às pautas e demandas das reivindicações estudantis, principalmente de mobilização para as reivindicações e as lutas por acesso aos direitos e ampliação desses direitos.

Discussões técnicas com Reitoria, Pró-reitorias, Diretorias, Gerências, Coordenações dos cursos e docentes, Coordenações e Núcleos para intermediar demandas de cancelamento, trancamento e/ou mudança de turno do curso, justificativas de faltas, transferência escolar, licença saúde e maternidade, atendimento domiciliar, entre outras. Apresentando, nesse processo, elementos das realidades estudantis referentes aos adoecimentos; às vulnerabilidades socioeconômicas, sociodigitais, socioemocionais, sociofamiliares; às subjetividades e necessidades objetivas de sobrevivências, que refletem desigualdades socioeconômicas estruturais impostas às/aos estudantes da classe trabalhadora, as/os quais precisam acumular $\mathrm{e}$ conciliar jornadas de trabalho aos estudos em busca de garantias da existência e subsistência.

É inconteste que as demandas estudantis e institucionais exigem respostas técnicas que possam ir além da intervenção imediatista e burocrática. Para tanto, é imperioso apropriar-se dos sistemas de mediação que "articulam o ser da profissão na dinâmica social [e vão se] estruturando histórica e processualmente [...], necessário se faz empreender uma verdadeira caça às mediações que se articulam na intimidade do tecido sócio-institucional” (PONTES, 2010, p. 172, acréscimos nossos), como dimensão teórica, técnica e ética que possibilita captar dialeticamente as contradições do real e apreender o ser social sob o prisma da totalidade.

\section{A PEDAGOGIA E SUA ASSISTÊNCIA ESTUDANTIL}

Nesta seção discutimos a assistência estudantil especificamente quanto ao trabalho de orientação educacional, de intervenção junto às famílias das/os estudantes e de harmonização das relações entre docente e discentes. Outra particularidade é que tal discussão brota do atendimento, sobretudo, a discentes adolescentes e jovens do Ensino Médio, que carecem de maior intervenção e acompanhamento profissional em função da maturação psicossocial e da complexidade de lidar, ainda, com os desafios dos cursos técnicos integrados a tal nível.

Geralmente a faixa etária presente nesse nível de ensino é de 15 a 17 anos, com sutil variação para mais ou menos. São adolescentes e jovens em mudanças físicas e psicológicas, em 
(trans)formação de suas identidades, que buscam referenciais e demonstram interesse em quem assume posições, de maneira que lhes permitam confrontar ou aderir. Experienciam cotidianamente os desafios e dificuldades do Ensino Médio, o que as/os leva à procura de estratégias de enfrentamento e de relações - entre pares e profissionais da instituição- que lhes sirvam de ancoragem. Inevitavelmente esbarram em adversidades que as/os impele ao encontro de quem as/os auxilie, quando seus recursos pessoais não dão conta. Suas cosmovisões e ideias também as/os move às relações com as/os profissionais, e por essas duas razões primárias, mas relevantes, reivindicam silenciosamente o direito legítimo de serem ouvidas/os. A trilha da escuta parece ser a cola que as/os une entre si e com as/os diferentes profissionais. É por ela que a/o pedagoga/o dá seus primeiros passos de acolhimento e compreensão, valorizandoas/os como sujeitas/os de fala, afinal "ouvir um jovem significa, antes de tudo, ter sido escolhido por ele para falar sobre algo”. (CONCEIÇÃO, 2010, p. 47).

A primeira dimensão que envolve a assistência estudantil pela/o profissional de Pedagogia, a nosso ver, está ligada à orientação educacional àquela/e interlocutora/or anteriormente mencionada/o. Na base dessa orientação está o cuidado dessa/e sujeita/o que se aproxima buscando conexão. Assistência expressa em orientação implica também em cuidar, e cuidar de outrem, num toque significativo, é "estar atento ao seu bem-estar, ajudá-la a crescer e atualizar-se, e para isso o outro é essencial”. (ALMEIDA, 2006, p. 42). Envolve alguma sintonia no sentir com a/o outra/o. Passamos a construir então uma relação suavemente afetiva e ao mesmo tempo pedagógica com ela/e, comprometidas/os a assisti-la/o em suas necessidades educativas daquele momento. Essa relação eu-outra/o, portanto, é intencional, peculiar, formativa e atenta aos cuidados demandados em cada contexto, para cada discente em seu estágio de desenvolvimento, quem nos impõe necessidades distintas e diferentes formas de atendimento.

Como parte desse cuidar, por essência acolhedor, a/o profissional escuta a queixa/dificuldade/impossibilidade da/o interlocutora/or, quem reflete com ela/e o objeto de sua fala, e nesse movimento dialógico a superação/solução, ainda que provisória, é construída por ambos ou pela/o profissional. Na dinâmica do trabalho cotidiano o diálogo, por vezes, pode ser furtivo, mas decisivo na diluição de suas inseguranças e dúvidas. O objetivo soberano é retomar o rumo da aprendizagem, e nesse aspecto orientar a/o estudante a (re)organizar sua rotina diária de estudos contribui com o processo e nutre a relação, especialmente quando percebe que nossa preocupação com seus interesses (e demandas) e o cuidado que lhe é dispensado são francos e legítimos. 
Outra dimensão que entendemos como imprescindível na atuação da/o pedagoga/o para assistir às/aos estudantes é a conexão com suas famílias, também atravessada pela escuta atenta, respeitosa e sem distinções. Interessadas/os em acompanhar o desenvolvimento das/os filhas/os, especialmente nos dois primeiros anos de curso, mães, pais ou responsáveis participam de reuniões coletivas na instituição ou buscam atendimento individualizado junto à equipe multidisciplinar, e, principalmente, à/ao profissional de Pedagogia para obter informações quanto à frequência e ao desempenho escolar. Na escuta, busca-se, de um lado, captar informações sobre o cotidiano familiar, a dinâmica das relações, as/os sujeitas/os com funções e papéis que assumem, conflitos e carências desintegradores e que podem afetar a saúde mental da/o estudante, o tipo de relação que mães, pais ou responsáveis estabelecem com a escola, suas expectativas e interesses; do outro, a escuta visa estabelecer vínculos de confiança, sem qualquer aproximação com uma escuta psicológica/terapêutica ${ }^{5}$.

Pisam no solo institucional uma pluralidade de famílias ${ }^{6}$, que em suas diferentes configurações e modos de vivenciar a relação com a escola requerem das/os profissionais atenção às suas peculiaridades socioeconômicas e culturais. A maior parte dessas famílias é economicamente empobrecida, apresenta baixo grau de escolaridade e é formada por mães/pais trabalhadoras/es diurnos, que em conjunto dificultam um acompanhamento sistemático do itinerário formativo das/os filhas/os. Diferente do que acontece na Educação Infantil, no Ensino Médio há um relativo grau de independização das/os mães/pais quanto a distintos aspectos da existência, entre eles o da vida acadêmica.

Pratta e Santos (2007) e Palácios e Oliva (2004) sublinham que, das mudanças físicas às psicossociais, a/o adolescente experimenta uma etapa crucial para seu desenvolvimento, etapa na qual deságua grande volume de experiências concretas (eventos) e psíquicas que culminarão na sua maturação enquanto adulta/o. Corresponde a uma etapa de descobertas das potencialidades e limites, de autoconhecimento, de definição de si, de questionamentos de alguns valores, normas e práticas familiares, pela busca da autoafirmação, de reconhecimento minucioso da imagem corporal, pela definição da identidade sexual e de gênero e da busca por integração social. Neste particular, é comum elas/es abandonarem parcialmente valores familiares, e incorporarem outros, notadamente de amigas/os. Podem lutar contra sentimentos de ansiedade, insegurança, angústia, depressão, autopercepção negativa, confusão e de injustiça

\footnotetext{
${ }^{5}$ Quando uma demanda estudantil como dificuldade de aprendizagem tem sua nascente em estados de ansiedade, depressão ou a qualquer outro fator fortemente vinculado ao psiquismo da/o sujeita/o, encaminhamos o caso à psicologia escolar, quem tem a competência técnica para intervir.

${ }^{6}$ Entre as principais: nucleares, monoparentais, reconstituídas/recasadas, ampliadas e homoparentais.
} 
diante da vida familiar, pensamentos (e tentativas) suicidas, podendo emergir conflitos entre os membros. (BALAZS et al., 2013; KESSLER et al., 2012).

A/O profissional de Pedagogia face a esse contexto procura interlocução, escuta as narrativas e, não raro, orienta, informa e educa. Como a mediação de conflitos é um território mais bem ocupado pela/o profissional da Psicologia, esta/e entra em parceria e ambos, em um movimento de escuta e fala com mães/pais, tentam a reconexão dos vínculos familiares. Nessa direção a atuação junto com e às/aos mães/pais se concentra no desenvolvimento de táticas de conflito que promovam conciliação e reações comportamentais não defensivas, focalizadas nos sentimentos e situação presentes e na expressão de atitudes menos reativas durante desentendimentos. (SILVA; CALHEIROS; CARVALHO, 2016).

Também reforçamos a necessidade de uma relação de interdependência entre famílias e escola para o êxito escolar da/o estudante, pois ambos são ambientes de desenvolvimento humano. (SOUZA, 2017; OLIVEIRA; MARINHO-ARAÚJO, 2010; DESSEN; POLONIA, 2007). Relação que se faz necessária ainda que as/os estudantes tenham atingido relativo grau de autonomia e independência em relação aos cuidados das/os mães/pais no quesito escolar. As/Os mesmas/os autoras/es, entre outras/os, ratificam a relevância da família para subsidiar -com amparo/afeto, proteção, subsistência- as trajetórias escolares de filhas/os adolescentes ou jovens; mas também sua ausência ou apoio deficiente pode contribuir no fracasso escolar e possível descontinuidade nos estudos.

Uma terceira forma de assistência à/ao estudante é junto à/ao docente, em especial nas situações de conflitos (os mais complexos são mediados com a participação da/o psicóloga/o escolar). Essas circunstâncias são singulares e demandam respostas também singulares. Situações que geram mal-estar e podem despotencializar a/o estudante, anemizar sua autoestima e cronificar a relação se a mediação e as/os envolvidas/os não encontrarem solução célere. $O$ relato de indisciplina em sala de aula é uma queixa comum, cuja reiteração mobiliza a/o docente a solicitar intervenção da/o pedagoga/o quando o diálogo com a/o estudante parece não resolver. $\mathrm{Da} /$ o discente também chegam relatos contra a/o mestra/e, criticando ou delatando problemas na relação professora/or-estudante (ex.: autoritarismo), no processo de avaliação da aprendizagem e no método de ensino adotado, supostamente disfuncional para turma.

Apesar de não haver uma receita pedagógica como método para lidar com esse contexto diverso, em nossa experiência temos praticado: i) a escuta das/os envolvidas/os, seja em tempos distintos seja simultâneo; ii) o registro de notas sobre pontos significativos de suas narrativas, emoções e movimentos, fragmentos de fala, que são dilatados com perguntas ou dúvidas que 
lhes expomos; iii) a análise da situação e as suas versões relatadas, e quando necessário contamos com o olhar multidisciplinar de outras/os profissionais; iv) a discussão de conclusões e propostas de soluções e v) a reunião das/os envolvidas/os para discuti-las. Como prevenção dessas e outras situações, nós pedagogas/os temos favorecido o processo de formação permanente das/os docentes na instituição, por entendermos que ela "significa provocar seu universo cognitivo, afetivo, social, para que [elas/es] desestabilizem, se mobilizem a novas atitudes, a novas práticas”. (PLACCO; SARMENTO, 2006, p. 42, acréscimo nosso).

\title{
EXPERIÊNCIAS PRÁTICAS EM PSICOLOGIA
}

Assim como as Escolas Técnicas sofreram grandes mudanças no processo de transformação em Institutos Federais, a prática da Psicologia dentro do IFS, nesse contexto, também teve que sofrer adaptações para que estivesse alinhada a esse novo modelo educacional, bem como as novas demandas estudantis que foram surgindo do final da década de $2000 \mathrm{em}$ diante. Isso pode ser apreendido a partir da argumentação a seguir:

\begin{abstract}
Considerando esses destaques que envolveram algumas das mudanças na Educação Profissional e Tecnológica no Brasil, é importante evidenciar a nova configuração da comunidade acadêmica nesses espaços. Os reforços institucionais quanto ao quantitativo e às diferentes categorias profissionais, constituídas por equipes multiprofissionais (psicólogos, pedagogos, assistentes sociais, profissionais da saúde); o percurso acadêmico oferecido aos estudantes nos Institutos Federais nos diferentes níveis de ensino e áreas de formação; o perfil heterogêneo de estudantes dos Institutos Federais; a defesa pela articulação entre a formação acadêmica e a formação profissional - todos esses fatores são destaques e desafios presentes no cotidiano para todos os atores educativos dos Institutos Federais, inclusive o psicólogo escolar. Cabe ressaltar que por meio da atuação desse profissional é possível contribuir para o fortalecimento de espaços formativos potencializadores do desenvolvimento humano da comunidade acadêmica. (FEITOSA; ARAUJO, 2018, p. 182).
\end{abstract}

Desde seu surgimento, a Psicologia escolar abrange uma grande gama de atividades bastante diversificadas e, a depender do referencial teórico e perspectiva social da/o profissional que executa estas tarefas, pode variar de quase exclusivamente atendimentos individuais, em uma atividade que se assemelha bastante à clínica, visando adequar a/o estudante "problemática/o" às rígidas normas escolares e ao padrão de normalidade socialmente estabelecido, quanto a um trabalho com uma visão mais coletiva e sistêmica que pensa na comunidade escolar e no corpo estudantil como um organismo vivo, pulsante e em movimento, direcionando suas ações à compreensão e intervenção nesses processos existentes.

No caso dos Institutos Federais, essa experiência de construção de uma prática da/o psicóloga/o escolar toma uma proporção ainda mais interessante, sendo ainda um tipo de 
profissional "optativo" legalmente dentro das escolas públicas e privadas. Nos Institutos Federais se estabelece uma recomendação que prevê a existência desta/e profissional em cada escola, ampliando consideravelmente a presença dessa/e profissional no quadro de servidoras/es da Rede de Educação Profissional, Científica e Tecnológica.

O atendimento psicológico no IFS - Campus Lagarto, em linhas gerais, consiste em intervenções individuais e/ou coletivas com o intuito de atuar em situações onde o comportamento humano esteja influenciando no desenvolvimento das/os estudantes dentro do contexto escolar. Esse atendimento visa atuar de forma direcionada e conjunta com a equipe multidisciplinar e com as/os demais profissionais que atuam no processo de ensinoaprendizagem e socialização das/os estudantes no Instituto, assim como em parceria com a rede de saúde e demais acompanhamentos que a/o estudante realize fora da instituição.

A solicitação desse tipo de intervenção pode acontecer de diferentes formas, seja a partir da demanda espontânea da/o estudante ou turma, que pode remeter-se diretamente à/ao profissional de Psicologia do Campus, ou por meio de indicação das/os professoras/es e/ou servidoras/es que atuam diretamente com as/os mesmas/os e tenham percebido alguma situação onde esse suporte seja necessário.

O serviço de Psicologia oferecido no Campus Lagarto inclui, entre as principais ações: 1. Atendimento individual estudantil (apoio psicológico, acolhimento, mediação de conflitos escolares, orientação profissional, métodos de redução de ansiedade escolar, etc.); 2. Acolhimento de demandas coletivas de intervenção diretamente nas turmas com a participação, ou não, das/os professoras/es do Campus e demais membros da equipe multidisciplinar, saúde escolar, entre outras/os; 3. Participação como apoio técnico nos planejamentos e reuniões da gestão e coordenadorias e 4. Acompanhamento de estudantes em conjunto com a equipe multidisciplinar (Serviço Social e Pedagogia).

Vale ressaltar, nesse contexto, a importância do trabalho sistêmico entre as/os profissionais de todos os campi do estado, realizado através de reuniões mensais, que foi iniciado desde que houve a ampliação da quantidade de Campus e consequentemente de concursos, quando ingressou mais da metade das/os psicólogas/os que hoje se encontra na instituição. De igual modo, possui relevância o trabalho multidisciplinar integrado que acontece entre as/os profissionais ligados à Assistência Estudantil do Campus, compreendendo assistência da forma mais ampla e universal possível.

Esse trabalho em conjunto dentro da mesma categoria ou com categorias afins possibilitou a realização de eventos amplos, abarcando toda comunidade do Instituto ou do 
Campus, alertando para o fato de que a saúde mental envolve todas/os as/os atrizes/atores envolvidas/os no processo educativo, e que se faz necessária uma atuação em conjunto para além das/os psicólogas/os ou das equipes multidisciplinares no que diz respeito às intervenções que devem ser realizadas diante das demandas coletivas que forem surgindo.

Outro ponto importante é o desafio que tem sido lidar ao mesmo tempo e no mesmo espaço com adolescentes em plena construção identitária que ainda não foram inseridas/os no mercado de trabalho, e com jovens adultas/os que já possuem trabalho e família e vivenciam uma realidade totalmente diferente, tendo assim também processos subjetivos bem diferentes na forma de serem compreendidas/os e manejadas/os na prática "psi".

Um grande desafio vivenciado pela/o profissional de Psicologia diz respeito à crença de que ela/ele realiza somente atendimento clínico terapêutico em qualquer contexto que trabalhe, essa ideia errônea faz parte do imaginário inclusive de boa parte das/os gestoras/es com quem precisamos trabalhar, assim como das/os estudantes e família das/os mesmas/os com as/os quais interagimos cotidianamente. Descontruir essa crença e apresentar as outras possibilidades de intervenção que podem ser realizadas, infelizmente tem ocupado um tempo precioso do dia a dia profissional das/os psicólogas/os.

Atuação profissional complexa e que assim como os Institutos está constantemente em construção e desconstrução, em busca de encontrar formas e ferramentas que nos permitam oferecer um serviço de qualidade às/aos estudantes, bem como contribuir para um ambiente de aprendizado, crescimento e socialização mais saudável.

\section{CONSIDERAÇÕES FINAIS}

O estudo contribui para a problematização de aspectos teóricos e analíticos da política de Educação e de Assistência Estudantil, ainda que sumariamente; e, a exposição reflexiva de métodos operacionais e dos processos de trabalho da atuação da equipe multidisciplinar de Psicologia, Pedagogia e Serviço Social em ações de acesso e permanência às/aos estudantes no âmbito da realidade sergipana, especificamente no IFS - Campus Lagarto, quadro que reflete demandas estudantis e experiências profissionais similares vivenciadas em outras instituições.

Diante do previamente exposto, podemos observar que o processo de assistência às/aos estudantes, para além das importantíssimas políticas de auxílio financeiro, consiste em diversas ações que levam em consideração as condições objetivas e subjetivas que envolvem o período de permanência das/os estudante na instituição de educação em que se desenvolvem essas práticas. A depender da especificidade, as demandas estudantis contam com intervenção da área 
técnica ligada ao aspecto apresentado; também, ao analisar determinados casos constatamos o conjunto de complexos, ou seja, a totalidade do ser social e as mediações que apontam a necessidade de atendimentos, acolhimentos e intervenções que acontecem de forma dialogada e planejada pela equipe multidisciplinar com ações em diversas frentes e áreas.

Assim como as instituições vão se construindo e se remodelando em diferentes contextos sociais e políticos, o trabalho da equipe multidisciplinar precisa estar em constante adaptação e diálogo com os desafios e novidades que surgem na realidade institucional. Apresentamos em nosso texto um recorte temporal e local das nossas práticas profissionais cotidianas, mas que em boa parte interagem com a realidade cotidiana de muitas/os profissionais nos Institutos Federais espalhados no país, justificando a relevância da investigação. Em futuras pesquisas, recorreremos às entrevistas, não exequíveis no momento, pois as narrativas oferecem elementos para aprimorar as intervenções e aprofundar as análises.

\section{REFERÊNCIAS}

ALMEIDA, Laurinda Ramalho de. O coordenador pedagógico e a questão do cuidar. In: ALMEIDA, Laurinda Ramalho de; PLACCO, Vera Maria Nigro de Souza. (Org.). O coordenador pedagógico e questões da contemporaneidade. SP: Loyola, 2006, p. 41-59.

BALAZS, J.; MIKLÓSI, M.; KERESZTÉNY, Á.; HOVEN, C. W.; CARLI, V.; WASSERMAN, C.; COTTER, P. Adolescent subthreshold-depression and anxiety: Psychopathology, functional impairment and increased suicide risk. Journal of Child Psychology and Psychiatry, 54, 2013, p. 670-677. Disponível em: http://dx.doi.org/10.1111/jcpp.12016. Acesso em: 16 set. 2020.

BETHLEM, Beatriz; MARTELLI, Maria Eugênia; DOMS, Caroline. Mãe solo: os desafios de criar os filhos sozinha. Repórter Unesp, 2019. Disponível em: http://reporterunesp.jor.br/2019/10/22/mae-solo-os-desafios-de-criar-os-filhos-sozinha/. Acesso em: 02 fev. 2021.

BRASIL. Decreto no 7.234, Dispõe sobre o Programa Nacional de Assistência Estudantil PNAES. de 19 de Julho de 2010. Diário Oficial [da] República Federativa do Brasil, Ministério da Educação, Brasília, 2010.

CFESS. Subsídios para a atuação de assistentes sociais na política de educação. Brasília, 2013.

CONCEIÇÃO, Lilian Feingold. Proposições e princípios para formação do estudante. In: Coordenação Pedagógica e orientação educacional: princípios e ações em formação de professores e formação do estudante. Porto Alegre: Mediação, 2010, p. 45-57.

DESSEN, M. A.; POLONIA, A. C. A família e a escola como contextos de desenvolvimento humano. Paidéia, Universidade de Brasília-UnB, Brasil, 17(36), 2007, p. 21-35. Disponível em: 
https://www.scielo.br/scielo.php?pid=S0103-

863X2007000100003\&script=sci arttext\&tlng=pt. Acesso em: 2 out. 2020.

FEITOSA, Lígia Rocha Cavalcante; ARAUJO, Claisy Maria Marinho. O papel do psicólogo na educação profissional e tecnológica: contribuições da Psicologia Escolar. Estud. Psicol., Campinas, v. 35, n. 2, Jun., 2018, p. 181-191. Disponível em: https://doi.org/10.1590/198202752018000200007. Acesso em: 4 out. 2020.

GUERRA, Yolanda. A dimensão investigativa no exercício profissional. In: Serviço Social: direitos sociais e competências profissionais. Brasília: CFESS/ABEPSS, 2009.

GUERRA, Yolanda. A instrumentalidade do Serviço Social. 9. ed. São Paulo: Cortez, 2011. IFS. Instituto Federal de Sergipe. Política de Assistência Estudantil do IFS, [aprovada através da] Resolução no 37/2017/CS/IFS, Aracaju, 2017. Disponível em: http://www.ifs.edu.br/politica-de-assistencia-estudantil-do-ifs-pae-ifs. Acesso em: 7 out. 2020.

KESSLER, R. C.; AVENEVOLI, S.; COSTELLO, E. J.; GEORGIADES, K.; GREEN, J. G.; GRUBER, M. J.; SAMPSON, N. A. Prevalence, persistence, and sociodemographic correlates of DSM-IV disorders in the national comorbidity survey replication adolescent supplement. Archives of General Psychiatry, 69, 2012, p. 372-380. Disponível em: http://dx.doi.org/10.1001/archgenpsychiatry.2011.160. Acesso em: 13 set. 2020.

NASCIMENTO, Ana Paula Leite. Uma análise das ações de assistência estudantil no contexto do Instituto Federal de Educação, Ciência e Tecnologia de Sergipe. 2014. Dissertação (Mestrado em Serviço Social) - Universidade Federal de Sergipe, São Cristóvão, 2014. 153p.

NASCIMENTO, Clara Martins do. Elementos conceituais para pensar a política de assistência estudantil na atualidade. FONAPRACE - Revista Comemorativa 25 anos: histórias, memórias e múltiplos olhares, Minas Gerais: UFU-MG, p.147-157, 2012.

PALÁCIOS, Jesús; OLIVA, Alfredo. A adolescência e seu significado evolutivo. In: COLL, C.; MARCHESI, A.; PALÁCIOS, J. Desenvolvimento Psicológico e Educação: psicologia evolutiva. 2. ed. Porto Alegre: Artmed, 2004, p. 309-322.

OLIVEIRA, C. B. E. de; MARINHO-ARAÚJO, C. M. A relação família-escola: intersecções e desafios. Estudos de Psicologia, Brasília, 1(27), 2010, p. 99-108. Disponível em: https://www.scielo.br/scielo.php?pid=S0103-

166X2010000100012\&script $=$ sci abstract\&tlng=pt. Aceso em: 23 set. 2020.

PAZ, Fabrício. Assistência, assistencialismo ou oportunismo estudantil? FONAPRACE Revista Comemorativa 25 anos: histórias, memórias e múltiplos olhares, Minas Gerais: UFUMG, 2012, p.192-195.

PLACCO, Vera Maria Nigro de Souza; SARMENTO, Maristela Lobão de Moraes. Outro jeito de dar aulas: orientação de estudos. In: GUIMARÃES, Ana Arhangelo. O coordenador pedagógico e a formação continuada. SP: Loyola, 2006, p. 37-42. 
PONTES, Reinaldo Nobre. Mediação e Serviço Social: um estudo preliminar sobre a categoria teórica e sua apropriação pelo Serviço Social. 7. ed. São Paulo: Cortez, 2010.

PRATTA, Elisângela Maria Machado; SANTOS, Manoel Antônio dos. Família e Adolescência: a influência do contexto familiar no desenvolvimento psicológico de seus membros. Psicologia em Estudo, Maringá, v. 12, n. 2, maio/ago., 2007, p. 247-256.

SILVA, Carla Sofia; CALHEIROS, Maria Manuela; CARVALHO, Helena. Interparental conflict and adolescents' self-representations: The role of emotional insecurity. Journal of Adolescence, 52, 2016, p. 76-88. Disponível em: https://doi.org/10.1016/j.adolescence.2016.07.007. Acesso em: 13 set. 2020.

SOUZA, Bárbara. O peso da maternidade solo durante a pandemia. Agência UVA, 2020. Disponível em: https://agenciauva.net/2020/10/13/o-peso-da-maternidade-solo-durante-apandemia/. Acesso em: 02 fev. 2021.

SOUZA, Fábio Kalil de. Notas sobre a relação família-escola na contemporaneidade. Rev. de Ciências HUMANAS, Florianópolis, v. 51, n. 1, jan-jun., 2017, p. 124-143. Disponível em: http://dx.doi.org/10.5007/2178-4582.2017v51n1p124. Acesso em: 14 set. 2020.

VASCONCELOS, Natalia Batista. Assistência Estudantil: uma breve análise histórica. FONAPRACE - Revista Comemorativa 25 anos: histórias, memórias e múltiplos olhares, Minas Gerais: UFU-MG, p.100-111, 2012. 